\title{
Knowledge Specialization, Knowledge Brokerage and the Uneven Growth of Technology Domains
}

\author{
Gianluca Carnabuci, University of Lugano \\ Jeroen Bruggeman, University of Amsterdam
}

Why do certain domains of knowledge grow fast while others grow slowly or stagnate? Two distinct theoretical arguments hold that knowledge growth is enhanced by knowledge specialization and knowledge brokerage. Based on the notion of recombinant knowledge growth, we show that specialization and brokerage are opposing modes of knowledge generation, the difference between them lying in the extent to which homogeneous vs. heterogeneous input ideas get creatively recombined. Accordingly, we investigate how both modes of knowledge generation can enhance the growth of technology domains. To address this question, we develop an argument that reconciles both specialization and brokerage into a dynamic explanation. Our contention is that specializing in an increasingly homogeneous set of input ideas is both more efficient and less risky than brokering knowledge. Nevertheless, specializing implies progressively exhausting available recombinant possibilities, while brokerage creates new ones. Hence, technology domains tend to grow faster when they specialize, but the more specialized they become, the more they need knowledge brokerage to grow. We cast out our argument into five hypotheses that predict how growth rates vary across technology domains.

\section{Introduction}

The ability of human societies to transform economic inputs into outputs of greater value, and hence to generate material wealth, rests on their technological knowledge (Jones 2005). In contrast to preliterate societies, where information about inventions circulated mostly by word of mouth (Diamond 2001), a distinguishing trait of the knowledge-based economy ${ }^{1}$ is that a considerable share of the existing technological knowledge is a public good (Mokyr 2002). Technological knowledge is a public good to the extent that it is clearly explicated and codified, and it is made widely available through media accessible at negligible costs, such as patents and technical literature (Arrow 1962). As most scholars agree, the growth of public technological knowledge has increased progressively during the past two centuries, yielding an unprecedented rate of economic growth (Jones 2005). The

The authors are grateful to Bernhard Kittel, Rob Mokken, Willem Saris, Joel Podolny, Frans Stokman, Bart Verspagen, the editor and three anonymous reviewers for their useful comments and suggestions. This research was supported by the Netherlands Organization for Scientific Research, NWO grant \#401-01-098. The first author is grateful to the Research Division of SDA Bocconi School of Management for its support. Direct correspondence to Gianluca Carnabuci, Institute of Management, University of Lugano, Via Buffi 13, 6904, Lugano, Switzerland. E-mail: gianluca.carnabuci@usi.ch. 
mechanisms and dynamics driving the growth of public technological knowledge, however, are still poorly understood.

In this research, we investigate why some domains of technology grow quickly while others grow slowly or stagnate (Nelson 2003). We understand the growth of technology as the extent to which new inventions engender new ideas and applications. Hence, our definition is in line with the notion that the growth of knowledge reflects both the number of new ideas generated and the extent to which these ideas are accepted (Simonton 2000; Walberg 1998; Weisberg 1993). To explain growth differentials across technology domains, we analyze the intertwined effects of two modes of knowledge generation that are commonly assumed to enhance knowledge growth in general. First, it has been argued that knowledge specialization facilitates the progress of knowledge by increasing the efficiency of the knowledge generation process, a notion that is at the core both of economic theory (e.g., Smith 1776; Walker 1867; Young 1928; Marshall 1936) and of bounded-rationality theories of learning (Simon 1977). Second, the argument that brokerage of knowledge across disparate domains yields novelty and thereby boosts knowledge generation, has recently become widespread in sociological publications (e.g., Burt 2004; Stuart and Podolny 1996; Sutton and Hargadon 1996).

Over the years, both the specialization and the brokerage arguments have gained substantial empirical support and many followers. However, the theoretical relation between knowledge specialization and knowledge brokerage has not yet been explicated in any detail. To relate the specialization and brokerage arguments, we build on the concept of "recombinant knowledge growth" (Weitzman 1996,1998 ) by taking the position that, whether generated through knowledge specialization or through knowledge brokerage, new knowledge always derives from recombinations of existing knowledge (Schumpeter 1939; Usher 1954; Weitzman 1998; Fleming 2001; Nolan and Lenski 2006). While the mechanism of knowledge recombination is common to both knowledge specialization and knowledge brokerage, we contend that the difference between these two modes of knowledge generation lies in the extent to which creative recombinations build on homogeneous rather than heterogeneous input. Hence, a technology domain is specialized to the extent that its new knowledge builds on a homogeneous set of closely related ideas; by the same token, the more that new knowledge builds on a wide spectrum of heterogeneous knowledge, the more that domain is brokering.

Seen from the perspective of recombinant knowledge growth, knowledge specialization and knowledge brokerage are therefore endpoints of one conceptual continuum, rather than distinct concepts. That is, the higher the degree of specialization of a technology domain, the lower its degree of brokerage, and vice-versa. But if a specialized domain is the opposite of a brokering domain, it follows that the growth of technological knowledge cannot be faster in both specialized and brokering domains at the same time, as the specialization and brokerage arguments would suggest if taken individually. To resolve this apparent paradox, we develop a theory 
that integrates the specialization and brokerage arguments into a dynamic explanation. The core of our thesis is that knowledge brokerage generates new opportunities for knowledge recombination, while these opportunities are more efficiently and more securely exploited through increasing knowledge specialization.

\section{The Salience of Technology Domains in Recombinant Knowledge Growth}

Public knowledge tends to diffuse in spite of geographic, organizational and social barriers, and it does not deplete with usage (Arrow 1962). Furthermore, new ideas spring from the novel combination of earlier ideas, and thus the input for future knowledge is existing knowledge (Gilfillan 1935; Schumpeter 1939; Usher 1954; Romer 1993). ${ }^{2}$ In his research, inspired by these considerations, economist Martin Weitzman proposed to conceive the growth of public knowledge as a process of "recombinant knowledge growth," which he represented mathematically as a combinatorial process (Weitzman 1996, 1998). Weitzman's modelling strategy captures elegantly what is arguably the most distinctive trait of the knowledge generation process, namely that because each new idea can potentially be recombined to produce multiple new ideas, knowledge growth tends to increase in scale. Allowing for a combinatorial explosion across the board, however, Weitzman's model fails to consider why knowledge grows in trajectories (Dosi 1982) and, in particular, why some trajectories grow faster than others (Nelson 2003). Furthermore, while in principle all ideas can be recombined with one another, there are numerous reasons why this does not happen. First, paraphrasing George Akerlof, ${ }^{3}$ one may wonder if combining chicken and ice cream is at all useful, or, said more generally, if all existing ideas can be recombined productively. Second, "[p]erceptions that certain technologies or components 'belong together' develop through social construction and previous association." For example, "if an electrical engineer of the 1940s had been asked about his profession's use of sand and aluminum, he probably would have replied with a blank stare. Today, he or she probably would reply that they are the most common basic materials of semiconductors and the focus of much research investment."(Fleming 2001:119) Third, the body of human knowledge is so large and dispersed (Hayek 1945) that only small portions of the potentially productive recombinations are envisioned, and even smaller portions materialize. Indeed, the creative recombination of ideas is a problem-solving endeavour characterized by limited information-processing capacity (Simon 1977), and is based on a highly incomplete and uncertain search (Fleming 2001). Thus unlike Weitzman's model, the actual processes of knowledge recombination through which new knowledge is generated can unfold in very different patterns across technology domains (or, for that matter, across individuals, firms, institutions, etc.) as well as over time. In line with this view, the goal of this research is to investigate how different dynamics of knowledge specialization and knowledge brokerage affect the rate of progress of technology domains. 
We believe that focusing on technology domains is particularly useful in studying the growth of public technological knowledge. One notable advantage is that one can simultaneously address the rate and the direction of knowledge growth, which would hardly be feasible when looking at individuals or organizations (see Dosi 1982). ${ }^{4}$ Meanwhile the variance observed across technology domains informs us about the mechanisms affecting knowledge growth in general, the direction of knowledge growth is determined by the growth rate of individual domains. Of course, paraphrasing Simon (1991), one may say that all inventions take place in the minds of individuals. As Simon was well aware, though, this does not mean that inventions take place in isolated individuals. To the contrary, inventions and inventors always build on existing technological knowledge and, in domains of technology, the body of received knowledge "is the necessary background against which new insight emerges."(Staudenmaier 1985:65) Thus, even the inventiveness of the most extraordinary genius and the most creative of organizations are deeply shaped by the state and evolution of the knowledge domain to which they are contributing, and this is true not just for technology (Rosenkopf and Tushman, 1998; Tushman and Rosenkopf 1992), but also for areas where the solitary work of genius is generally regarded as quintessential, such as philosophy (Collins 1998), art (Becker 1982) and mathematics (Davis and Hersh 1980). Progress in a technology domain is thus the result of an inherently social process, and quite often it happens that an inventor builds on technological knowledge generated by someone he or she does not even know (Ziman 1967; Knorr-Cetina 1999). To study the growth of public technological knowledge, therefore, a vantage point may be gained by focusing on the network of knowledge recombination at the level of technology domains, even if this comes at the cost of remaining agnostic about other relevant units of analysis such as "organizations, individuals, or other combinations of actors."(Marquis and Davis 2005:337) From this perspective, inventors and organizations are then seen as relatively denser clusters of ideas within a knowledge recombination network, possibly linking "...multiple communities with highly specialized technologies and knowledge domains.”(Boland and Tenkasi 1995:350; Brown and Duguid 2001) ${ }^{5}$

\section{Recombinant Knowledge Growth as an Evolving Network of Technology Domains}

To formally define and, subsequently, empirically measure knowledge specialization and knowledge brokerage at the level of technology domains, we use a network-analytic approach. Technology domains may be thought of as cross-sectional "slices" of technological trajectories (Nelson and Winter 1982). And indeed, the notion that technological knowledge grows along trajectories of accumulation implies that the bulk of inventive knowledge recombination takes place within distinct technology domains, very similar to scientific disciplines being the loci of scientific knowledge production. However, like scientific knowledge in one discipline often spawns innovations in another, inventions developed in a technol- 

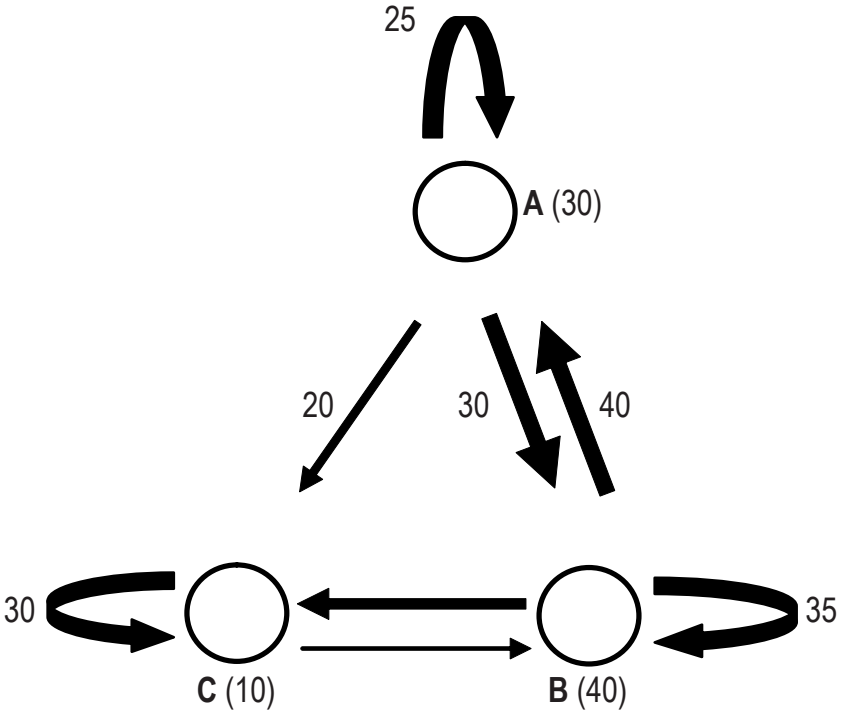

ogy domain can serve as an input for inventions in other domains. Recombinant knowledge growth can thus be modelled as an evolving network of technology domains, where arcs (i.e., valued and directed ties) indicate patterns of inventive recombination both within and across domains. Figure 1 is an example of such a network which depicts a cross-cut of the growth process of a hypothetical stock of public technological knowledge within a given time window. This stock consists of three technology domains, A, B and C, in which 30, 40 and 10 new inventions, respectively, have accumulated over the given time interval. The arcs point to the domains from which ideas are taken and are drawn in the direction of knowledge search. Knowledge flows in the opposite direction of the arrows, though, and in the literature on diffusion (Rogers 2003), arrows are in line with the flows. ${ }^{6}$ The inventions generated in A resulted from the recombination of inventions from A's own knowledge base 25 times, from B's 30 times, and from C's 20 times. Or, equivalently, knowledge spilled over 25 times from past to current inventions in $\mathrm{A}$, 30 times from past inventions in $\mathrm{B}$ to current inventions in $\mathrm{A}$ and 20 times from past inventions in $\mathrm{C}$ to current inventions in A. During the same time interval, the inventions generated in $\mathrm{A}$ worked as an input for inventions in B 40 times, i.e., ideas spilled over from A to B 40 times.

Formally, a network $N_{t}$ at time interval $t$ is a four-tuple, $\left\langle N_{t}=J_{t}, L_{t}, V_{t}, A_{t}\right\rangle$ that consists of a finite set of nodes, $J_{t}=\{i, \ldots, k, q, \ldots, j\}$, a finite set of $\operatorname{arcs}$ (i.e., directed ties) between the nodes, $L_{t}=\left\{l_{i k, t}, \ldots, l_{q j, t}\right\}$, a function $V_{t}($.$) mapping arcs$ onto pertaining arc values $h$ (i.e., tie weights), and a function $A_{t}($.$) mapping nodes$ onto node values. Nodes represent technology domains and their values represent knowledge output. The arc value $h_{i j}$ represents the number of times that ideas 
belonging to the right-hand subscript node have been used in idea-combinations of the left-hand subscript node, and arc directions point to the nodes where ideas have been taken from.

\section{A Network View on Domains Specialization and Brokerage}

Intuitively, a technology domain is specialized insofar as it grows through the recombination of a homogeneous body of closely related knowledge. In contrast, a domain is brokering insofar as it grows by recombining ideas across a broad spectrum of mutually unrelated technological areas. To flesh out and to model this intuition, our starting point is a domain's recombinant niche (i.e., the sub-network comprising a focal domain), the domains from which it recombines ideas (the source domains), the valued and directed ties linking the focal domain to its source domains, and the valued and directed ties linking source domains among each other. ${ }^{8}$

In general, the degree of brokerage in a focal node's niche indicates the extent to which the focal node brokers between otherwise disconnected nodes (Burt 1992). Applied to our network model, the brokerage of a domain's niche indicates a pattern of knowledge recombinations from domains that in their turn do not recombine knowledge from one another or from the focal domain. Accordingly, the degree of brokerage of a domain's recombinant niche indicates the extent to which its underlying technological community, in the aggregate, brings together knowledge across unrelated and, thus, heterogeneous source domains (Figure 2, Panel A). Conversely, a domain with high specialization recombines closely related knowledge (i.e., knowledge from either the focal domain itself) or from domains that are strongly related among each another and to the focal domain (Figure 2, Panel C). Figure 2 shows four hypothetical domains, ranging from low specialization (Panel A) to high specialization (Panel D).

\section{Theory and Hypotheses}

Having posited specialization and brokerage as opposites on a continuum, we are left with the paradox that, according to extant theory and empirical evidence, both specialization and brokerage enhance knowledge growth. To resolve this paradox, and to specify a theory of knowledge growth where the effects of specialization and brokerage are explicitly related, it is necessary to distinguish between specialization as a property and as a process. Applied to a technology domain, specialization is a property indicating that, at a given point in time, ideas are recombined from a homogeneous body of closely related knowledge. For example, our data show that the technology domain of "mechanical guns and projectors" is highly specialized (like Panel D in Figure 2) while, in contrast, the domain of "coating processes" is highly brokering (like Panel A). Seen dynamically, specialization indicates the process by which ideas are recombined from a body of increasingly related knowledge. For example, the domain of "superconductor technology: apparatus, material, 
Figure 2. From A to D, Increasing Specialization of Focal Technology Domain

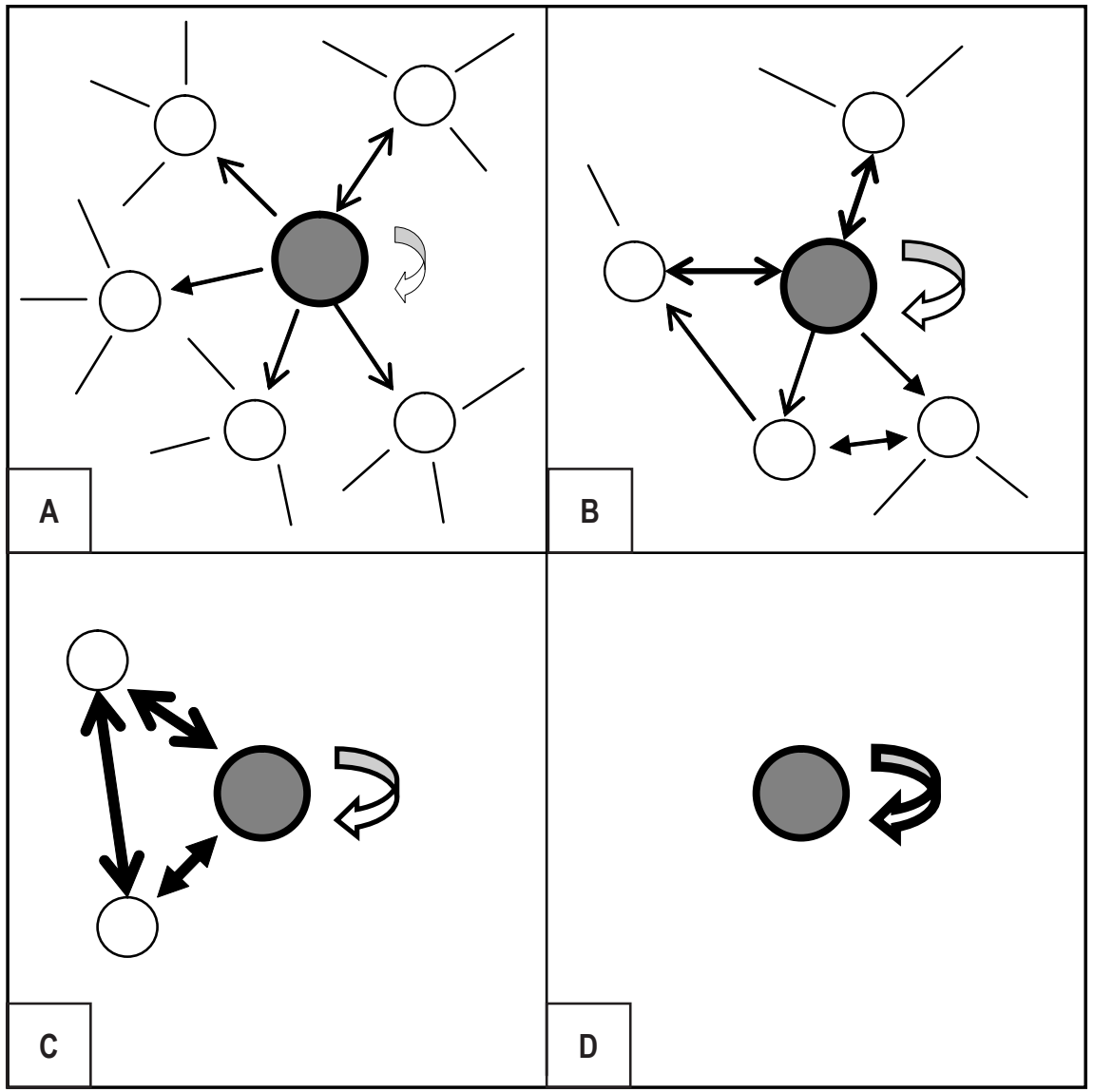

process" became much more specialized between the beginning and the end of the 1990s. The property vs. process distinction is not generally made in literature. As we aim to show, however, revisiting knowledge brokerage and knowledge specialization in light of this analytical distinction helps to reconcile the two concepts in a unitary theory.

The central claim of the brokerage argument is that the more mutually unrelated are the ideas one is exposed to, the more innovative (on average) are the ideas one generates (e.g., Burt 2004). The knowledge recombination perspective makes it possible to spell out the causal mechanism underlying this claim. The ideas that an actor (in our case, a technological community) is exposed to provide the input that the actor considers in knowledge recombination. Thus, in general, the more one is exposed to ideas that are unrelated, the more abundant and diverse are the potential new combinations and, therefore, the more numerous and innovative the ideas generated. Supporting this view, Holyoak and Thagard (1995) have shown at the individual level that creative transfers of ideas occur 
by shifting mental models in a cross-fertilizing fashion. Regardless of the specific cognitive mechanisms involved, being confronted with ideas from diverse knowledge domains and applications prompts unexplored mental representations, thereby exposing potentially useful relations between previously unrelated ideas (Anderson and Thompson 1989; VanLehn and Jones 1993). A well-known example is Gutenberg's printing press, which resulted from the combination of ideas from the disparate bodies of knowledge that Gutenberg had studied, including metallurgy, press, ink, movable type and the alphabet (Diamond 1997). Literature overflows with similar accounts of other inventions (Mokyr 2002). More systematic empirical evidence is reported by Dunbar (1996), among others; he showed that scientists working in teams with a greater diversity of scientific backgrounds tend to solve problems by conceiving more innovative solutions. Evidence is also provided by Burt (2004), who found that firm employees embedded in brokering networks generate more numerous and creative ideas.

The benefits of recombining knowledge from diverse domains extend beyond the individual, resulting in more creative artistic and academic teams (e.g., Guimerà, Uzzi, Spiro and Amaral 2005) and organizations (e.g., Hargadon 2002). Notice that, at these aggregate levels, knowledge can also be recombined by pooling members with distinct specializations. Thus, the beneficial effects of knowledge brokerage derive from the aggregate spectrum of ideas that a team, organization or community draws from collectively, whether through individuals with knowledgebrokering competencies (such as Gutenberg) or through the pooling of knowledge from individuals with diverse specialties. Applying the brokerage argument to the level of technology domains therefore suggests that the amount and the novelty of potential recombinations available to a technological community depend on how heterogeneous is the stock of public knowledge residing within the community's recombinant niche (as captured by Figure 2). This leads us to our first hypothesis:

\section{H1: The higher the degree of brokerage of a technology domain at a given point in time, the higher its subsequent growth rate; similarly, the higher the degree of specialization of a domain at a given point in time, the lower its subsequent growth rate.?}

If knowledge brokerage increases both the amount of recombinant opportunities and their novelty, it follows that knowledge specialization reduces both of them. What, then, are the benefits of knowledge specialization? Seen another way, what are the limits of knowledge brokerage? An obvious scope condition is that while knowledge brokerage and knowledge specialization are opposite modes of knowledge generation, their effects are to some extent complementary; indeed, the expected benefits of knowledge brokerage would vanish in the absence of knowledge specialization. That established, we contend that the relation between knowledge specialization and knowledge brokerage can be fully understood only 
from a dynamic perspective. While technological growth is enhanced by the abundant recombinant opportunities associated with a high degree of knowledge brokerage (brokerage as a property), the positive impact of knowledge specialization rests on the fact that recombinant opportunities are more efficiently exploited by increasing specialization (specialization as a process). Applied to the context of technology domains, when a domain grows through increased knowledge specialization, knowledge is recombined more efficiently, i.e., with lower marginal costs. In contrast, when a technology domain grows through increased brokerage (i.e., when a technology domain is in the process of de-specializing), the marginal costs of knowledge recombination are much higher.

To elaborate, we define the specialization of a technology domain as the extent to which it recombines ideas from a homogeneous body of knowledge. Starting from a highly brokering niche (Figure 2, Panel A), the homogeneity, and thus specialization, of a domain can increase in four ways. First and foremost, a technological community may draw a progressively larger fraction of its total recombinant inputs from the domain's knowledge base, thereby increasing the proportion of "self" recombinations. Second, a community may concentrate on fewer source domains, thereby progressively shrinking its recombinant niche. In both cases, specialization increases as a result of exploitation, i.e., by increasing the depth and reducing the scope of knowledge recombination patterns (Katila and Ahuja 2002), consonant with theory elaboration and integration in scientific research programs (Wagner and Berger 1985, 1986). Figure 1, however, shows that the homogeneity of a domain's recombinant niche may also increase in two indirect ways. The source domains may become progressively more homogeneous due to an increased recombination of ideas among one another; and, a source domain may become progressively more similar to the focal domain by recombining a larger proportion of its recombinant inputs from the focal domain. ${ }^{10}$

In short, our argument is that the more the progress of a technology domain is achieved through progressive specialization, the greater the efficiency gains associated with exploiting an increasingly familiar and homogeneous recombinant niche. By combining ideas from the same subset of the technological landscape in a path-dependent fashion, exploitation increases familiarity with these ideas (Fleming 2001). At the individual level, familiarity with a subject matter due to accumulated experience enables the individual to handle larger chunks of information, thereby facilitating knowledge recollection and application (Chase and Simon 1973), which helps him/her to search for, appreciate and pursue potential recombinations (Simonton 2000; Walberg 1988). Furthermore, problems related to familiar knowledge can be more effectively and more efficiently decomposed into simpler sub-problems (Eisenhardt and Tabrizi 1995). Familiarity with a new technology domain, however, can be achieved only at the price of high, fixed learning costs (Hayes 1989; Simonton 1991), typically requiring a substantial amount of domain-specific tacit knowledge (Gavetti and Levinthal 2000) and many years 
of preparation even for talented individuals (Weisberg 1993). Therefore, there is a scale advantage to spreading fixed learning costs over a relatively larger knowledge output, and "[i]t is only when one has hit the frontier of one's primary specialization, where new items of interest are hard to find, that it might be cheaper to learn items outside that specialty."(Postrel 2002:306)

The efficiency gains associated with the process of specialization are amplified at higher levels of aggregation, where knowledge is recombined by actors dispersed throughout an organization or a technological community. In these cases, familiarity with the recombinant niche also results in more widely shared "embedding circumstances" (for example, with regard to the technical jargon, instruments and testing criteria used in the inventive process), and thus it is associated with more effective and efficient communication. Moreover, in the context of public knowledge, every new relation that is established among ideas and inventions within a recombinant niche effectively homogenizes the knowledge therein; this, in turn, progressively reduces the cognitive and technical distances among a community's recombinant inputs. In summary, due to the efficiency gains associated with the exploitation of an increasingly homogeneous and familiar recombinant niche, knowledge growth tends to be faster when technology domains advance by progressive specialization. By the same token, these efficiency advantages are lost when knowledge is recombined in a de-specializing fashion, i.e., when a domain's recombinant niche becomes more heterogeneous and knowledge brokering. Accordingly, domains' growth rates should be lower during those times when previously unrelated knowledge enters a domain's recombinant niche.

\section{H2: The more the degree of specialization of a domain increases during a given time period, the higher its growth rate in that period; similarly, the greater the increase of brokerage, the lower the growth rate.}

In addition to efficiency losses, exploratory recombinations and knowledge brokerage entail higher unpredictability. Although both exploitation and exploration are uncertain processes that may or may not yield knowledge growth, exploitation rests on known uncertainties involved in recombining knowledge from a more familiar niche, whereas exploration is based on unknown uncertainties inherent in distant search (March 1991; Fleming 2001; Cohen and Aston-Jones 2005). Notably, exploitation reduces the probability of dead ends because failed recombination attempts indicate less successful parts of a familiar recombinant niche (Fleming 2001; Vincenti 1990). When one ventures into brokering previously unexplored domains, hardly any prior information is available within the focal community regarding fruitless combinations that should be avoided. Furthermore, brokering knowledge means de-embedding knowledge from one community and re-embedding it in another; this entails passing more arduous cognitive and 
cultural barriers (Brown and Duguid 2001), and it may trigger political intricacies and irrational factors whose effects are hard to predict (Latour 1987). When Edison invented the light bulb, he was accused of "the most airy ignorance of the fundamental principles of electricity and dynamics." (quoted by Hargadon 2002:57) However, in addition to a greater risk of failure, and consistent with both Edison's experience and Hypothesis 1, brokering knowledge through explorative recombinations is also more likely to generate unusually fruitful inventions due to the greater innovative potential inherent in recombining heterogeneous knowledge inputs. These arguments lead to our third hypothesis:

\section{H3: There is greater variance in growth rates among highly brokering technology domains than among highly specialized ones.}

As stated by Hypothesis 2, the greater the increase in the degree of specialization of a technology domain during a given time interval, the higher we expect its growth rate to be (net of differences in the number and novelty of inputs available in the domain's recombinant niche). In line with Hypothesis 1, though, the number and novelty of input potentially available for recombination vary inversely with a domain's degree of specialization, for three reasons. First, as experience accumulates, most of the recombinations in a domain's niche have already been tried. Second, when a domain becomes more specialized, its recombinant niche becomes more homogeneous, and thus the recombinant inputs that remain are more likely to yield cumulative refinements of existing ideas than to yield breakthrough inventions. Third, being exposed to increasingly unambiguous and taken-for-granted methods may engender a habit of reproducing those methods and understandings at all costs (March 2005), thus reducing actors' ability and willingness to search for path-breaking solutions (Levinthal and Rerup 2006). Therefore, the higher the level of specialization of a domain, the greater the likelihood that the efficiency gains associated with a further increase in specialization will be offset by a lack of creative input and seminal ideas. From these arguments it follows that the effects of increasing specialization are inversely proportional to a domain's degree of specialization.

\section{H4: The positive effect of increasing specialization on a domain's growth rate becomes less pronounced as domain's degree of specialization rises, eventually reaching a point where a further increase in specialization hampers the domain's growth rate.}

Our first four hypotheses focused on the relation between domains' specialization and brokerage on the one hand, and the (variance in) domains' growth rates on the other hand. Specifying hypotheses where the dependent variable is a 
change variable allows us to test postulated causal relationships more directly and unambiguously than can be done through level variables (Hsiao 2003). However, our theoretical arguments can also be extended to predict a level variable-the knowledge output accumulated within a domain during a given time interval. To appreciate the difference between the two types of dependent variables, consider the following example. Our first four hypotheses attempt to explain why, between the early 1990s and the late 1990s, the knowledge output generated in the technology domain "internal-combustion engines" grew by one fourth and the knowledge output generated in the technology domain "mineral oils: processes and products" decreased by one fourth. However, our first four hypotheses are silent about the absolute size of domains' knowledge output in the late ' 90 s, which for "internal-combustion engines" is about three times as large as for "mineral oils: processes and products."

Synthesizing H1, H2 and H4, the following argument can be postulated about the absolute size of domains' outputs. While a brokering domain has greater recombinant potential for future growth than a specialized domain, that potential is realized only to the extent that the heterogeneous inputs in its recombinant niche are progressively related to one another through exploitation-driven recombinations. However, the longer this process continues, the higher the degree of specialization reached by a domain and the fewer and less path-breaking are the potential recombinations left to sustain the domain's future advancement. Together, $\mathrm{H} 1$, $\mathrm{H} 2$ and $\mathrm{H} 4$ entail that (1. a domain characterized by low specialization (i.e., high brokerage) has not exploited its recombinant potential, while conversely (2. a highly specialized (i.e., low-brokerage) domain has already exhausted most of it. Thus (3. on average, the absolute size of accumulated knowledge output should be largest when a domain is at intermediate levels of specialization (and brokerage), when its pertaining technological community can carry out abundant exploitative recombinations within a still sufficiently heterogeneous recombinant niche. These arguments lead us to our fifth hypothesis.

\section{H5: The absolute size of the knowledge output generated in a technology domain within a given time interval varies concavely with the domain's degree of specialization.}

\section{Data and Operationalization}

To test our theory, we have chosen what is probably the largest stock of public technological knowledge, a database that describes all of the patented inventions (more than 2 million), and all of their citations (more than 16 million), granted by the United States Patent and Trademark Office in 1975-1999 (Hall, Jaffe and Trajtenberg 2001). We use the USPTO data to indicate (1. the nodes of our knowledge recombination network, i.e., technology domains, (2. the ties connecting these domains, signalling knowledge recombination patterns, and (3. the 
domains' growth rates. On the basis of this network, we will then operationalize our explanatory and response variables.

\section{Technology Domains}

The USPTO has expert patent classifiers who examine the claims made in each application document. After the content of an application has been analyzed, the application is classified according to a set of well-specified criteria. According to the 1999 concordance scheme, the United States Patent Classification features 418 three-digit, or primary, classes of technological knowledge, and more than 120,000 subclasses. For the nodes of our network we chose to use the former, for four reasons. First, primary classes correspond more closely to well-circumscribed technologies or industrial sectors, and are therefore more reliable and robust than other partitions (Henderson, Jaffe and Trajtenberg 2005). Second, while some patents contribute to more than one subject, patents are assigned to only one primary class based on their "main inventive content," i.e., their most important knowledge contribution as perceived by the patent examiner (Earls, Smith, Wolf, Saifer, Rishell, Russell and Rademaker 1997). Because primary classes do not overlap, in contrast to subclasses, only the former can be unambiguously operationalized as nodes in a network. Third, patents are periodically reassigned to patent classes in a retrospective fashion to reflect the emergence of new technological domains or the disappearance of existing ones. Clearly, the more narrowly one defines the technology domains the shorter the time scale within which these structural changes occur. Within our observation period, reassignments have been extremely rare at the level of primary classes, while they have been in the thousands at the level of subclasses. This makes primary classes a preferable unit of analysis for our research purposes. ${ }^{11}$ Fourth, there are about 400 primary patent classes, which is a large yet manageable sample size.

Although the examiners' judgement is to some extent subjective, we believe that the combination of the USPC system with the examiners' expertise yields high levels of accuracy, reliability and inter-subjectivity. Moreover, there is an extensive body of literature that uses patent classes to indicate technology domains. For example, Powell and Snellman (2004) used patent classes to trace the changing importance of technological sectors over time. Similarly, patent classes have been used to measure technological proximity by, among many others, Almeida (1996); Jaffe and Trajtenberg (1999); Hicks, Breitzman, Olivastro and Hamilton (2001); and Frost (2001). Also, in studies at the national level, patent classes frequently have been used to measure countries' technological specialization and technological advantage (Soete 1987; Patel and Pavitt 1987; Cantwell 1989; Patel and Vega 1999).

Furthermore, whether the USPC technological classification is in part a social construction matters less for our research purposes. Our argument is that inventors operating in different technological communities are exposed to different recombinant niches. Thus, our assumption is that inventors busy with power plant 
technologies, for example, will try to keep stride with and build on the inventions within that domain. They will search the USPTO database through the USPC technological classification scheme, whether that reflects an entirely objective representation of the underlying domain or not. The result of that search will shape the recombination inputs to which they are exposed and thereby, according to our theory, the amount and novelty of new knowledge they are able to generate.

\section{Knowledge Recombination Patterns}

Patents cite earlier patents, pointing out that public knowledge inventions draw from prior art. Thus, patent citations are indicative of the recombination process underlying the creation of an invention. Following Griliches' seminal work (1979), in the past few decades many scholars, especially in the field of applied economics, have exploited patent citations to investigate the dynamics of knowledge recombination. In addition to the indirect validation provided by such large body of empirical work, Jaffe, Fogarty and Banks (1998) devised a validity test of patent citation indicators, concluding that patent citations are "a valid but noisy measure of technology spillover," a finding later confirmed by Jaffe and Trajtenberg (2002). Certainly, patent citation data must be treated with caution. Alcácer and Gittelman (2006) used new data available since 2001, making possible to disentangle the patent citations made by inventors from those added by patent examiners, and concluded that taking individual patent citations as indicators of knowledge recombination yields a risk for both type I and type II errors. Despite these risks, however, overall there is ample evidence that patent citations are a useful indicator of knowledge recombination. Furthermore, unlike many prior studies, we do not focus on individual patent citations, but on aggregated patterns at the level of technology domain. As Alcácer and Gittelman's (2006) study showed, at this level of aggregation the patent citations added by the patent examiners do not significantly differ from those inserted by the inventors. Finally, it is important to note that we are interested in how recombinant niches, capturing the different exposition of technological communities to recombinant inputs, affect knowledge growth. From this perspective, patents' prior art provides us with the information we're after-i.e., the recombinant inputs that are most immediately visible. Thus, paradoxically, when there is a difference between the actual recombination inputs used for an invention and the ones inferred from the prior art of the patent document, it may be argued that for us the latter are more relevant, given that they are the ones that are most likely to be retrieved (and thus recombined) by inventors interested in the focal patent.

\section{Network Evolution}

In our model, we represent USPC three-digit technology domains as nodes and citations of patents in one domain by patents in other domains as arcs, where arc weights indicate the number of citations and arrows point into the direction 
Figure 3. The Network of Patented Technological Knowledge Production in the USA

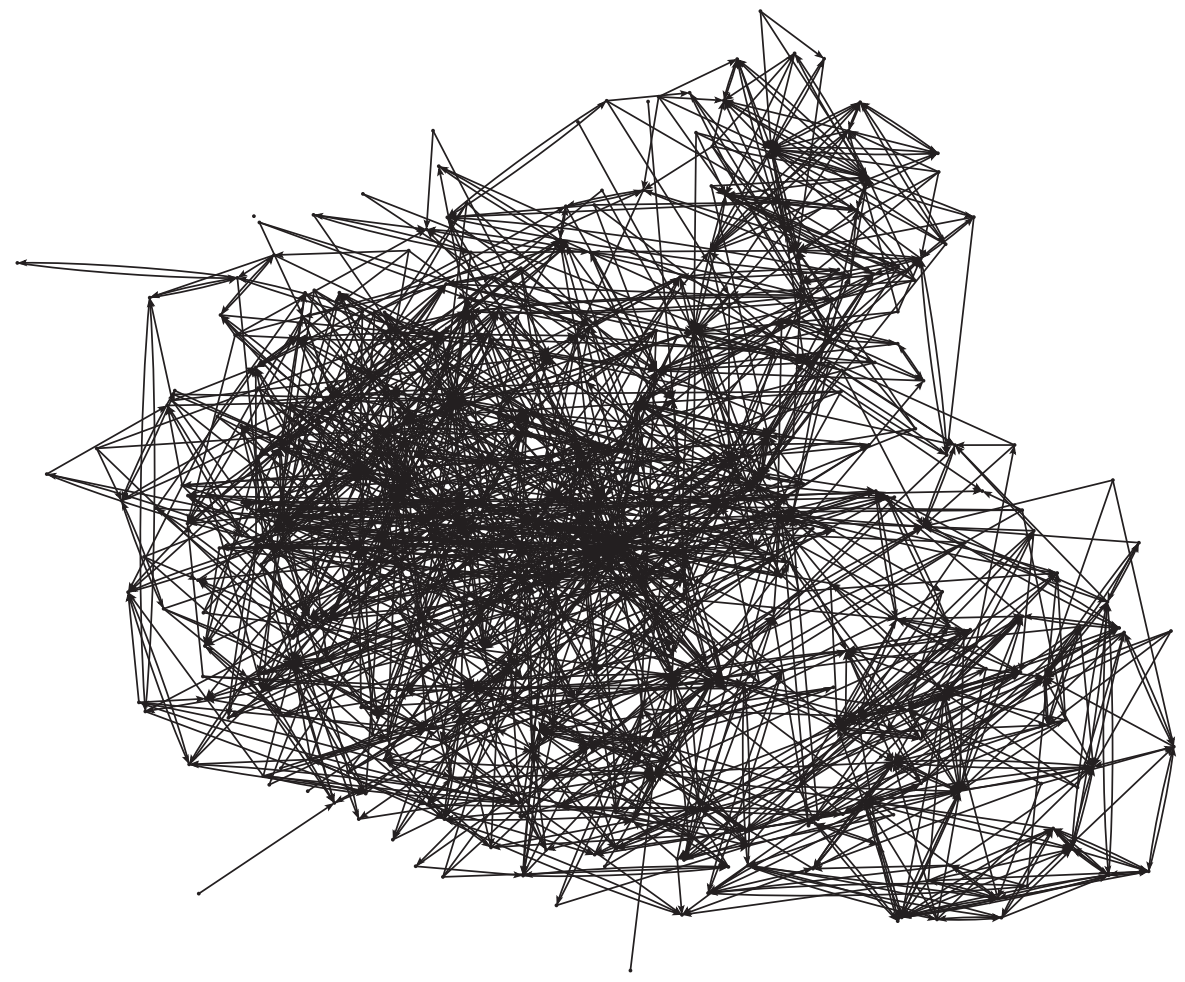

of citations. ${ }^{12}$ Based on all knowledge patented in the United States 1975-1999, Figure 3 shows the network of knowledge recombinations between technology domains. The network is highly connected because, on average, a domain has at least one patent citation to more than half of the other domains; the highest arc values are of domains citing themselves. The thickets created by the weakest 5 percent of the ties and by the reflexive ties have been omitted; if they had been included, the representation would be too dense for readers to see any network.

For the remainder of our analyses, in order to capture the evolution of the network we partitioned the observation period into five-year intervals, following Podolny and colleagues (1996). Clearly, this truncation yields a bias if domains' citations of older patents systematically point to different technology domains than do more recent citations. We assessed the magnitude of this bias by a Quadratic Assignment Procedure (Krackhardt 1987, 1988), regressing the network based on the most recent five-year windows (1995-1999) on the entire 25-year observation period (1975-1999). This analysis showed that the two network configurations yielded a correlation coefficient as high as .999 ( $\mathrm{p}<.001)$, thus indicating that a network representation based on a five-year interval is as unbiased as one based on the 25 -year period. To avoid spurious relationships between the variables of interest, we then opted to model our knowledge recombination networks as a 
time series of five non-overlapping networks, for the following time intervals: 1975-1979, 1980-1984, 1985-1989, 1990-1994 and 1995-1999.

\section{Domains' Growth}

For an invention to be patented, it must consist of knowledge that is new, nontrivial and applicable. Therefore, a patent is, by definition, an idea that advances the stock of public technological knowledge. Accordingly, patent counts are generally regarded as a valuable proxy for measuring knowledge growth if the success of each patent is taken into account (Grilliches 1990). If a patented invention consists of knowledge that is useful for the generation of subsequent inventions, it will be cited. In the words of Gittelman and Kogut (2003:380), "because certain patents open richer technological veins, the subsequent advances in related technical knowledge encourage more innovative efforts in that area and, hence, more patents. These, in turn, cite the initial patents that opened this avenue of technological innovation. It is this feedback that carves a trace in the patent patterns." Accordingly, a widely used indicator of the impact of a patent is the number of citations it receives (Griliches 1990). As validation that a patent's forward citations capture knowledge contribution, these citations were found to be positively related to received royalties (Giummo 2003), to intangible assets after controlling for R\&D expenditure (Hall et al. 2005), to the value of a patent in the eyes of the patent holder (Harhoff et al. 1999), and to the social value of a patent (Trajtenberg 1990). Forward citations were also directly validated as a measure of knowledge contribution through surveys of inventors and experts by Albert et al. (1991), and by Jaffe et al. (2000). No published study in the large body of empirical research on the topic has disconfirmed the validity of this measure.

At the level of technology domains, we measure knowledge output by counting all the patents granted within a domain over a given time interval, weighed by the number of forward citations they received. Because it weighs each patent by the number of forward citations it received, our measure is consistent with the well-established notion that any quantification of knowledge output must reflect both the number of new ideas generated and the extent to which these ideas gain recognition (Simonton 2000; Walberg 1998; Weisberg 1993; Fleming 2007). Call our knowledge output measure $M_{i t}$, where $i$ indicates all domains in our study population and $t=\{1975-1979,1980-1984,1985-1989$, 1990-1994, 1995-1999\}. To calculate a domain's growth rate, we then take the percentage difference between the domain's knowledge outputs in subsequent time intervals: $\left(M_{t+1}-M_{t}\right) / M_{t}$. The choice to confine the measure of domains' knowledge output within a five-year interval may engender an error, given that less than 30 percent of citations are made to patents less than five years older than the original patent. It takes some 50 years to capture 90 percent of all citations received by a patent (Hall et al. 2001), which is well beyond our observa- 
tion period. To assess the magnitude of this error, we took all patents granted in each domain during the first five-year interval (1975-1979), and counted the citations they received during the same period. Then we counted the citations received by those same patents up to the year 1999, and we calculated the correlation between the two measures. Both Pearson's and Spearman's rho values were above .97 and highly significant $(\mathrm{p}<.001)$, indicating that it is acceptable to measure domain's knowledge output, and thus domain's growth rate, on the basis of five-year intervals.

\section{Domain's Specialization and Brokerage}

To model for each domain $i$ knowledge specialization and knowledge brokerage, as illustrated by Figure 2, we adapt Ron Burt's well-established network brokerage measure (Burt 2004, 1992). In Burt's model, brokerage is the opposite of constraint, while in our model, brokerage $\left(B_{i}\right)$ is the opposite of specialization $\left(S_{i}\right)$, which we define as $B_{i}=1-S_{i}$. The concise form of our specialization model is expressed by Equation (1); time indices are left out for ease of reading.

$$
S_{i}=\Sigma_{j}\left(p_{i j}+\Sigma_{q} p_{i q} p_{q j}\right)^{2}
$$

When $i$ has no arcs, we leave $S_{i}$ undefined because, in our conceptualization, a domain that carries out no recombination is neither specialized nor brokering. Let us start by fleshing out $p_{i j}$, which, as in Burt's model, indicates proportional tie strengths of $i$ s direct contacts, here the proportion of ideas taken, and thus $0 \leq p_{i j} \leq 1$. For our knowledge recombination model, a few changes are necessary with respect to Burt's model, the most important of which is the inclusion of arcs of nodes to themselves (see Figure 1), by allowing for the possibility that $i=j$ (Equation 5). Then there are three more issues to consider when $i \neq j$. First, our specialization model should capture well that if source domain $j$ frequently takes ideas from focal domain $i$ while $i$ only rarely takes ideas from $j$, then $i$ is not highly specialized in $j$ (although $i$ is constrained by $j$ in Burt's model), and hence $p_{i j}$ should in our model be small. Second, if $i$ is highly specialized in ideas from $j$ while $j$ is highly specialized in ideas from $i$, then $p_{i j}$ should approach 1 . Third, if $i$ takes ideas a given number of times from $j$ and if $j$ takes more ideas from $i$ that to some extent funnel back to $i$, then $i$ 's level of specialization is higher and $p_{i j}$ should have a higher value, accordingly. To express these three requirements for $i \neq j$, we first define a term $s_{i j}$ that is independent of $j$ s specialization on $i$,

$$
s_{i j}=\frac{h_{i j}}{\sum_{k} h_{i k}} \text {. }
$$

The index variable $k$ indicates all of the nodes in $i$ s ego network, that is, all nodes that $i$ draws from directly, including $i$ itself. The arc value, $h$, is the number of times that ideas belonging to the right-hand subscript node are used in combinations of the left-hand subscript node. The same story can be told from $j$ 's point 
of view (again $i \neq j$ ),

$$
s_{j i}=\frac{h_{j i}}{\sum_{l} h_{j i}} .
$$

The index $l$ denotes the nodes in the ego network of $j$, including $j$ itself. ${ }^{13}$ By combining (2) and (3), we can define $p_{i j}$ in a way that meets our requirements,

$$
p_{i j}=S_{i j} S_{j i}
$$

If the focal domain has an arc to itself $(i=j)$, we define $p_{i i}=S_{i i}$.

For definitions of proportional tie values for indirect contacts with $j$ via $q$ (where $q$ is also in $i$ 's ego network, and $q \neq i$ and $q \neq j$ ) we follow Burt (1992). ${ }^{14}$ Corresponding to our informal description of the process of specialization (Figure 2), Model (1) and its satellite definitions of proportional tie strength make clear that the increased specialization of focal domain $i$ can happen in four ways. First, it can happen by an increase in the proportion of self-recombinations ( $p_{i i}$ increases). Second, when the focal domain increases its concentration on a limited number of source domains ( $s_{i j}$ increase). Third, when there are more strongly interrelated source domains ( $p_{q j}$ increase). Fourth, when source domains use proportionally more ideas from the focal domain ( $s_{j i}$ increase), which partly return to the focal domain later on (depending on a given value of $s_{i j}$ ). Finally, to measure how is specialization changes between subsequent time intervals, we subtract is prior level of specialization from is current level of specialization. ${ }^{15}$

\section{Analysis}

\section{Statistical Methods}

There are four sources of possible non-independence in our data. First, timevarying factors could affect the growth of all technology domains in a similar way; these may include macro-economic fluctuations, the rapid generic increase of both the number of patents and the number of citations (Hall et al. 2001), and changing practices among USPTO officers, etc. To model these temporal effects, we use period dummy variables. Second, non-independence could also occur within subsets of units, as Hall et al. (2001) have shown by pointing out similarities in patenting and citation patterns within six USPC macro-technological areas ("1-digit" classification). Again, we model these effects by means of dummy variables. Third, as domains are interconnected by knowledge flows, non-independence may also yield network autocorrelation; that is, the growth of a technology domain may affect the growth of its contact domains. To account for this specific kind of nonindependence, we adopt an established method in the social network literature and use a network disturbance model (Leenders 2002). ${ }^{16}$ Finally, the fourth kind of non-independence that could arise in the context of our study is related to 
the panel structure of our data. There may be unobserved heterogeneity across technology domains; thus, repeated observations within units are likely to be more similar than between units in our data. For example, certain technology domains may inherently have greater potential for growth than other domains, for reasons that are either unknown to or unobserved by the researcher. We exploit the panel structure of our data to account for this possible unobserved heterogeneity, using both a fixed-effects and a random-effects model to test our hypotheses. ${ }^{17}$

\section{Results}

Our dependent variable-the domains' percentage growth rate-is distributed along a fairly well-behaved Gaussian curve, with very few outlying observations featuring exceptionally high values (i.e., 10 times the population mean). All of the outliers correspond to very small technology domains, which could explain why their percentage growth rate is so high. To ensure that our estimates are not unduly influenced by a few peculiar cases, we removed all observations in which a domain's growth rate between two subsequent time intervals was higher than 10 times the population mean. This resulted in the removal of six observations. Postestimation analyses of the residuals confirmed the appropriateness of this choice. Further, we removed all observations corresponding to technology domains that received no citations at all during a given time interval (again, corresponding to very small technology domains), because the concepts of recombinant niche, specialization and brokerage are meaningless in those cases. Lastly, we removed from the analyses the technology domain called "miscellaneous" because it is merely a residual class in the USPC patent system. As a result of these choices, our sample decreased from 1,672 observations to 1,639 observations. ${ }^{18}$

In Table 1, we report descriptive statistics and a correlation matrix for all of the variables used in our analysis. Table 2 shows the results of our statistical test, on which we focus now. Models 1 and 3 are baseline models within the fixed-effects and random-effects frameworks, respectively; Models 2 and 4 add a triplet of covariates representing hypotheses 1,2 and 4 to models 1 and 3. Because most inventions are made within firms, we controlled for the log of the number of firms operating in a domain at $t$, which turns out to have a negligible effect on a domain's percentage growth in all models. Furthermore, some authors have argued that the proportion of backward patent citations that firms make to their own patents is indicative of their ability to exploit their own inventions, which in turn may have repercussions on firms' knowledge strategies and investments (Hall et al. 2001). To make sure these firm-level dynamics do not affect our estimates of interest, we calculated for each domain the average number of firm self-citations during each time interval and used it as a control. According to our analysis, firms' ability to exploit their own inventions has a positive effect on domains' growth rates, but the effect is statistically significant only in Model 3. Our measure of specialization does not look at individual patents but rather at the aggregate recombination pat- 


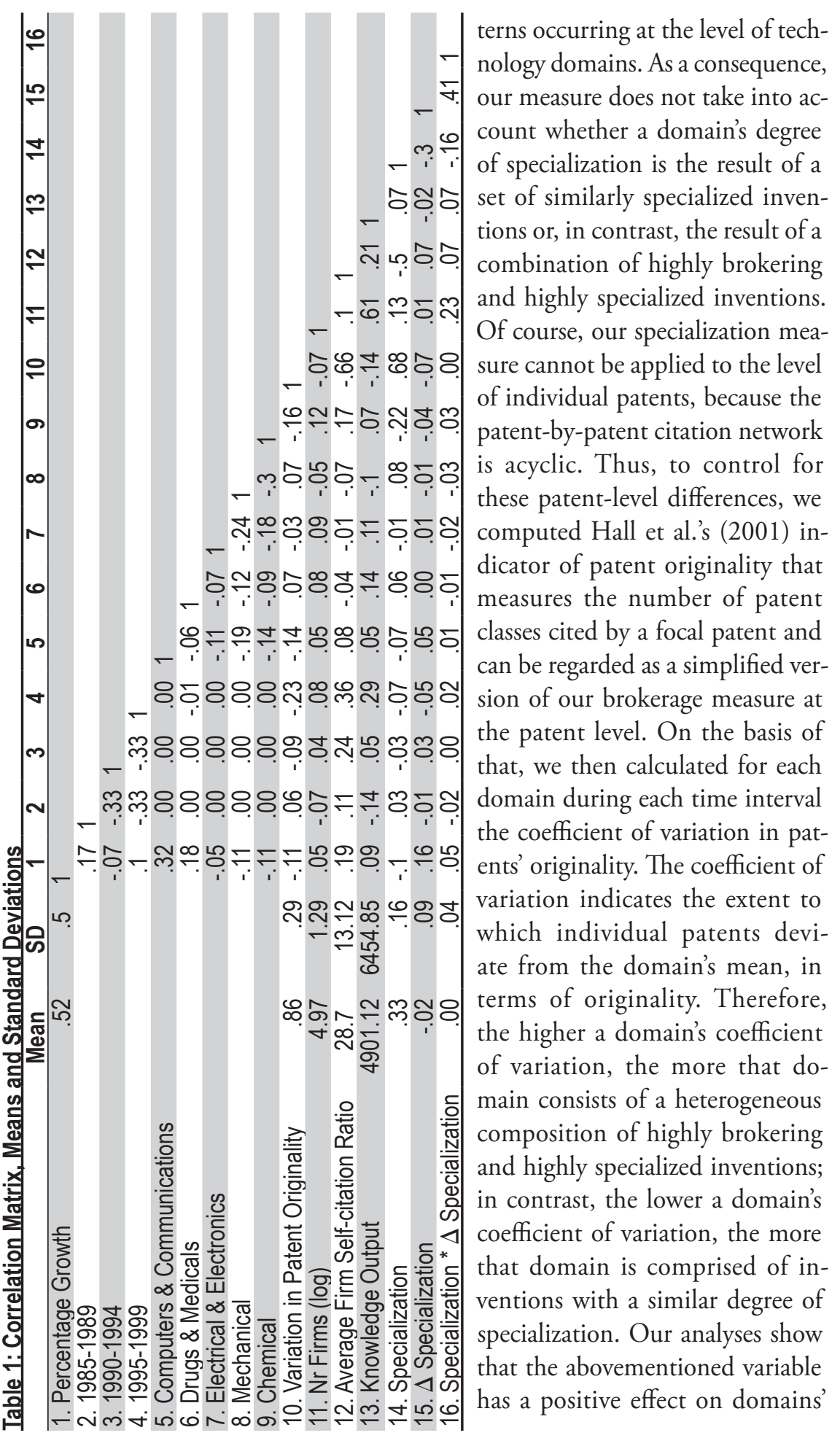


growth rates, but the effect is statistically significant only after the hypothesized effects of specialization are accounted for. In line with previous analyses (Hall et al. 2001), we find a strong positive (albeit non-monotonic) relationship between time and a domain's growth; as a reference category, we used the first time interval in our observation period, 1975-1979. Furthermore, models 3 and 4 show that the technology domains belonging to the areas of "computers \& communications" and "drugs \& medicals" (which includes biotech) have grown the fastest over the observation period, and have grown significantly faster than domains in our reference category, i.e., the miscellaneous category "others." In contrast, the domains "chemicals" and "mechanical technologies" have grown significantly more slowly than the reference category.

In the last three rows of the table, we report the estimates pertaining to our first three hypotheses. All three hypotheses are statistically supported within both the fixed-effects and the random-effects specifications. As predicted by Hypothesis 1, specialized domains grow, on average, slower than brokering ones. Namely, according to our fixed-effects estimates, a difference of one standard deviation in the level of specialization of a technology domain results in an 18 percent decrease in the growth rate achieved in the subsequent five years. Conversely, as predicted by Hypothesis 2, the process of specialization is positively associated with growth. Thus, a technology domain that increases its specialization by one standard deviation over a given time period sees its growth rate increase during that period by 4.5 percent. However, as predicted by Hypothesis 4, the positive effect of increasing specialization is reversed for high levels of specialization. A one standard deviation increase in specialization in a highly brokering technology domain $(S \cong .05)$ yields a growth rate that is 10 percent larger than when no specialization occurs and, if the process of specialization is more rapid, this difference can be as high as 36 percent. Conversely, for a technology domain characterized by a relatively high degree of specialization, the effect of further specialization is altogether reversed. For example, for a level of specialization of $S \cong .45$, a one standard deviation increase in specialization leads to a 52 percent decrease in growth rates.

To test Hypothesis 5, we estimated both a fixed-effects (Model 5) and a randomeffects model (Model 6) along the lines of models 1 through 4, making the response variable a level variable-knowledge output accumulated in a domain within a given time interval-rather than a change variable. Hypothesis 5 stated that the volume of knowledge generated in a technology domain within a given time interval has an inverted U-shaped relationship with a domain's degree of specialization. To model this non-monotonic relationship, we jointly estimated the effects of domain's specialization and the effects of domain's squared specialization. In Table 3 , we report the results of the test, according to which the inverted hypothesized U-shaped relationship between specialization and knowledge output is statistically highly significant. ${ }^{19}$ Namely, the effects of specialization are initially associated with larger volumes of accumulated output but become negative after some point. 
- Social Forces 88(2)

Table 2: Dynamic Effects of Specialization and Brokerage on Domains' Percentage Growth

\begin{tabular}{|c|c|c|c|c|}
\hline Dependent Variable: & Fixed & Effects & Randon & Effects \\
\hline Domain's \% Growth & Model 1 & Model 2 & Model 3 & Model 4 \\
\hline Intercept & $\begin{array}{l}.132 \\
(.56)\end{array}$ & $\begin{array}{r}-.011 \\
(-.05)\end{array}$ & $\begin{array}{l}.276^{* \star \star} \\
(2.90)\end{array}$ & $\begin{array}{l}.166 \\
(.16)\end{array}$ \\
\hline 1985-1989 (Reference: 1980-1984) & $\begin{array}{l}.279^{* * \star} \\
(6.44)\end{array}$ & $\begin{array}{l}.323^{* * *} \\
(7.44)\end{array}$ & $\begin{array}{l}.245^{* * *} \\
(5.97)\end{array}$ & $\begin{array}{l}.313^{* * *} \\
(7.48)\end{array}$ \\
\hline 1990-1994 (Reference: 1980-1984) & $\begin{array}{r}.072 \\
(1.48)\end{array}$ & $\begin{array}{l}.106^{* *} \\
(2.12)\end{array}$ & $\begin{array}{l}.035 \\
(.80)\end{array}$ & $\begin{array}{l}.101^{* *} \\
(2.30)\end{array}$ \\
\hline 1995-1999 (Reference: 1980-1984) & $\begin{array}{l}.211^{* * *} \\
(3.91)\end{array}$ & $\begin{array}{l}.257^{* \star *} \\
(4.57)\end{array}$ & $\begin{array}{l}.175^{* * *} \\
(3.84)\end{array}$ & $\begin{array}{l}.265^{\star * *} \\
(5.65)\end{array}$ \\
\hline $\begin{array}{l}\text { Computers \& Communications } \\
\text { (Reference: Others) }\end{array}$ & & & $\begin{array}{l}.617^{* * *} \\
(11.88)\end{array}$ & $\begin{array}{l}.608^{* * *} \\
(11.97)\end{array}$ \\
\hline Drugs \& Medical (Reference: Others) & & & $\begin{array}{l}.574^{* * *} \\
(7.63)\end{array}$ & $\begin{array}{l}.562^{\star * *} \\
(7.63)\end{array}$ \\
\hline Electronic (Reference: Others) & & & $\begin{array}{l}-.026 \\
(-.59)\end{array}$ & $\begin{array}{l}-.036 \\
(-.82)\end{array}$ \\
\hline Mechanical (Reference: Others) & & & $\begin{array}{l}-.073^{* *} \\
(-2.12)\end{array}$ & $\begin{array}{l}-.071^{* *} \\
(-2.09)\end{array}$ \\
\hline Chemicals (Reference: Others) & & & $\begin{array}{l}-.137^{* * *} \\
(-3.42)\end{array}$ & $\begin{array}{l}-.137^{* * *} \\
(-3.42)\end{array}$ \\
\hline Number of firms (log) & $\begin{array}{c}.014 \\
(.31)\end{array}$ & $\begin{array}{l}.023 \\
(.50)\end{array}$ & $\begin{array}{l}-.003 \\
(-.29)\end{array}$ & $\begin{array}{l}.006 \\
(.53)\end{array}$ \\
\hline Average Firm Self-citation Ratio & $\begin{array}{r}.003 \\
(1.47)\end{array}$ & $\begin{array}{l}.001 \\
(47)\end{array}$ & ${ }^{.004^{* * *}}$ & $\begin{array}{l}.001 \\
(.81)\end{array}$ \\
\hline Variation in Patent Originality & $\begin{array}{r}.121 \\
(1.45)\end{array}$ & $\begin{array}{l}.265^{* * *} \\
(3.15)\end{array}$ & $\begin{array}{l}.014 \\
(.24)\end{array}$ & $\begin{array}{c}.114^{*} \\
(1.69)\end{array}$ \\
\hline Specialization & & $\begin{array}{l}-1.133^{* * *} \\
(-4.46)\end{array}$ & & $\begin{array}{l}-.342^{* * *} \\
(-275)\end{array}$ \\
\hline$\Delta$ Specialization & & $\begin{array}{l}.484^{* * *} \\
(2.44)\end{array}$ & & $\begin{array}{l}.967^{* \star *} \\
(6.18)\end{array}$ \\
\hline Specialization * $\Delta$ Specialization & & $\begin{array}{l}-1.354^{* * *} \\
(-2.89)\end{array}$ & & $\begin{array}{l}-1.006^{* * *} \\
(-2.63)\end{array}$ \\
\hline of Units & 415 & 415 & 415 & 415 \\
\hline Periods & 4 & 4 & 4 & 4 \\
\hline Number of Observations & 1,639 & 1,639 & 1,639 & 1,639 \\
\hline $\begin{array}{l}\text { R-Squared (Within) } \\
\text { Log Likelihood }\end{array}$ & .111 & .156 & $-1,016.8$ & -985.4 \\
\hline
\end{tabular}

Hence, the domains that accumulate the largest knowledge output within a fiveyear interval are neither extremely specialized nor extremely brokering, but rather hover around the middle (the maximum being reached when $S=.6$ ).

Finally, to test Hypothesis 3, we compared the variance in growth rates exhibited over the observation period by highly brokering and highly specialized domains. To identify the two groups, we took the top 10 percent of domains with the highest levels of brokerage and the top 10 percent of domains with the high- 
Table 3: Effects of Specialization and Brokerage on Domains' Knowledge Output

\begin{tabular}{|c|c|c|c|c|}
\hline Dependent Variable: & Fixed & Effects & Randol & n Effects \\
\hline Domains' Knowledge Output & Model 5 & Model 6 & Model 7 & Model 8 \\
\hline Intercept & $\begin{array}{l}7.046^{* * *} \\
(91.52)\end{array}$ & $\begin{array}{l}5.901^{* * *} \\
(56.58)\end{array}$ & $\begin{array}{l}6.506^{\star * *} \\
(41.36)\end{array}$ & $\begin{array}{l}5.182^{* * \star} \\
(32.08)\end{array}$ \\
\hline 1980-1985 (Reference: 1975-1979) & $\begin{array}{l}.263^{* * *} \\
(6.53)\end{array}$ & $\begin{array}{l}.182^{* * *} \\
(4.88)\end{array}$ & $\begin{array}{l}.276^{* * *} \\
(6.91)\end{array}$ & $\begin{array}{l}.174^{* * *} \\
(4.70)\end{array}$ \\
\hline 1985-1989 (Reference: 1975-1979) & $\begin{array}{l}.731^{\text {*** }} \\
(16.61)^{-1}\end{array}$ & $\begin{array}{l}.662^{* * *} \\
(16.29)\end{array}$ & $(17.14)$ & $\begin{array}{l}.653^{* * *} \\
(16.20)\end{array}$ \\
\hline 1990-1994 (Reference: 1975-1979) & $\begin{array}{l}1.102^{* * *} \\
(23.19)\end{array}$ & $\begin{array}{l}1.035^{* * *} \\
(23.58)\end{array}$ & $\begin{array}{l}1.118^{* * *} \\
(23.85)\end{array}$ & $(23.59)$ \\
\hline 1995-1999 (Reference: 1975-1979) & $\begin{array}{l}1.556^{* * *} \\
(3.26)\end{array}$ & $\begin{array}{l}1.531^{* * *} \\
(32.33)\end{array}$ & $\begin{array}{l}1.574^{* * *} \\
(31.08)\end{array}$ & $\begin{array}{l}1.524^{* * *} \\
(32.63)\end{array}$ \\
\hline $\begin{array}{l}\text { Computers \& Communications } \\
\text { (Reference: Others) }\end{array}$ & & & $\begin{array}{l}1.199^{* * *} \\
(4.17)\end{array}$ & $\begin{array}{l}1.279^{* * *} \\
(4.87)\end{array}$ \\
\hline Drugs \& Medical (Reference: Others) & & & $\begin{array}{l}1.317^{* * *} \\
(3.12)\end{array}$ & $\begin{array}{l}1.187^{* * *} \\
(3.08)\end{array}$ \\
\hline Electronic (Reference: Others) & & & $\begin{array}{l}.905^{* * *} \\
(3.64)\end{array}$ & $\begin{array}{l}.961^{* * *} \\
(4.24)\end{array}$ \\
\hline Mechanical (Reference: Others) & & & $(1.00)$ & $\begin{array}{l}.175 \\
(.98)\end{array}$ \\
\hline Chemicals (Reference: Others) & & & $\begin{array}{l}.757^{* * *} \\
(3.47)\end{array}$ & $\begin{array}{l}.979^{* * *} \\
(4.91)\end{array}$ \\
\hline Average Firm Self-citation Ratio & $\begin{array}{l}.001 \\
(.56)\end{array}$ & $\begin{array}{l}.004^{* * *} \\
(3.07)\end{array}$ & $\begin{array}{l}.000 \\
(.27)\end{array}$ & $\begin{array}{l}.005^{* * *} \\
(3.42)\end{array}$ \\
\hline Variation in Patent Originality & $\begin{array}{l}.145^{* *} \\
(2.27)\end{array}$ & $\begin{array}{r}-.102 \\
(-1.65)\end{array}$ & $\begin{array}{l}.157^{* *} \\
(2.51)\end{array}$ & $\begin{array}{l}-.106^{*} \\
(-1.74)\end{array}$ \\
\hline Specialization & & $\begin{array}{l}5.787^{* * *} \\
(13.95)\end{array}$ & & $\begin{array}{l}6.713^{* * *} \\
(16.60)\end{array}$ \\
\hline Specialization Squared & & $\begin{array}{l}-4.637^{* * *} \\
(-9.15)\end{array}$ & & $\begin{array}{l}-5.820^{* * *} \\
(-11.78)\end{array}$ \\
\hline Number of Units & 415 & 415 & 415 & 415 \\
\hline Periods & 5 & 5 & 5 & 5 \\
\hline Number of Observations & 2,045 & 2,045 & 2,045 & 2,045 \\
\hline $\begin{array}{l}\text { R-Squared (Within) } \\
\text { Log Likelihood }\end{array}$ & .720 & .764 & -184.378 & $-1,667.287$ \\
\hline
\end{tabular}

Notes: Random effects models are estimated by Maximum Likelihood Estimation $t$ ratios in parenthesis.

${ }^{* * *} p<.001 \quad{ }^{* *} p<.01 \quad{ }^{*} p<.05$

est levels of specialization as measured during the first time interval. To account for possible fixed effects in the growth patterns of domains, we transformed the response variable in deviations from unit means; hence, the variance observed reflects the extent to which a domain's growth rate over time deviates from the domain's own mean. Our hypothesis is that the growth rates of domains that were highly brokering during the first time interval will exhibit greater variance over the observation period than those of highly specialized domains. As predicted, the variance in growth rates is larger for the group of brokering domains than for the specialized ones, and the difference is highly significant according to Levene's test (1960). (See Table 4.) A glance at the confidence intervals for the means gives a 
Table 4: Variance Ratio Test of Within-Domain Percentage Growth

$95 \%$ Confidence Intervals

\begin{tabular}{lcccccccc} 
Groups & $\mathrm{N}$ & $\mathrm{T}$ & Observation & Mean & SD & SD Error & Min & Max \\
\hline High Brokerage & 41 & 4 & 157 & 0 & .762 & .060 & -.120 & .120 \\
High Specialization & 41 & 4 & 163 & 0 & .433 & .034 & -.067 & .067 \\
\cline { 1 - 1 } Levene test & 121.40 & & & & & & & \\
\cline { 1 - 1 } & 0 & & & & & & & \\
\hline
\end{tabular}

sense of how differently the two modes of knowledge generation operate. Within a 95 percent confidence interval, the growth rate of a brokering domain is nearly twice as volatile as the growth rate of a specialized domain.

\section{Conclusions}

\section{Contributions of the Study}

We believe that the present study yields three main contributions to the extant literature. First, it clears up the widely used notions of knowledge brokerage and knowledge specialization, showing more precisely what they are and how they relate to each another. As noted by Postrel (2002), task or labor specialization on the one hand and knowledge specialization on the other should not be confused. While task specialization may entail knowledge brokerage, and a brokering task may be based on highly specialized knowledge, knowledge specialization and knowledge brokerage define opposite patterns of knowledge recombination. The focus of this study was on the generation of knowledge, regardless of the underlying organization of tasks. Therefore, we departed from the commonly used empirical strategy of looking at firm-, network- or industry-level knowledge growth, and focused our attention directly on the growth of technology domains. In so doing, we were able to explicitly take into account that knowledge specialization and knowledge brokerage are opposite modes of recombinant knowledge growth, and explicate how their putative effects are dynamically intertwined.

In contrast to earlier studies that treated specialization and brokerage as independent drivers of knowledge growth, we used a large set of longitudinal data to demonstrate that knowledge brokerage creates a recombination potential that can be efficiently exploited only by a process of increasing knowledge specialization. Moreover, we showed that increasing specialization enhances knowledge growth at a declining rate, and that therefore the process of specialization is either alternated by knowledge brokerage or it will ultimately lead to stagnation. The picture that emerges from our analyses is congruent with descriptive accounts of the evolution of science (Kuhn 1962), and of industries (Abernathy and Utterback 1978; Dosi 1982; Tushman and Anderson 1986; Utterback and Suarez 1993), where progress reportedly results from long periods of path-dependent, incremental refinements within a given research program or paradigm, sometimes alternated with path-breaking paradigm shifts. Whether and to what extent these phenomena are 
driven by oscillating regimes of knowledge specialization and knowledge brokerage are intriguing questions, as well as opportunities for future research. While bibliographic records are more cumbersome to deal with than patents, they could nonetheless serve as a useful starting point in examining whether our arguments apply to the development of scientific fields (De Solla Price 1965).

From a normative standpoint, our findings are compatible with the view that to maximize knowledge growth, a balance must be struck between knowledge specialization and knowledge brokerage. Borrowing from March (2005:9), knowledge specialization tends to increase a desire for the purification of existing ideas, yielding "exquisite barrenness," while knowledge brokerage entails the glorification of the newest recombinations, yielding shallow ideas produced in "cascades of triviality." In line with this view, we find the technology domains that generate the most knowledge are neither too specialized nor too brokering. Our results also show that looking at knowledge growth from a static perspective makes little sense, and that any fixed position on the specialization-brokerage continuum is doomed to be sub-optimal. The issue is not to find the most productive point along the specialization-brokerage continuum. Rather, it is to oscillate between knowledge brokerage (to generate new veins of productive recombinant inputs when the wells start to dry out) and knowledge specialization (to efficiently exploit those recombinant opportunities). While timely switching between these two opposite modes of recombinant knowledge growth is likely to be hard, our theory warns against convenient yet non-efficacious equilibria.

As a second contribution, the present study extends our understanding of how public technological knowledge accumulates. A distinguishing trait of the knowledge-based economy is that a large share of newly generated technological knowledge is a public good (Mokyr 2002). Most scholars agree that, since the Scientific Revolution, the rate of accumulation of public technological knowledge lies at the base of unprecedented yet sustained economic growth (Jones 2005). The mechanisms driving the accumulation of public technological knowledge, however, have hardly been studied and, to date, recombinant growth in the context of public knowledge is modelled as an unrealistically unconstrained combinatorial process (Weitzman 1996, 1998). This research took up the challenge to identify how specialization and brokerage affect the returns of knowledge recombination in the context of public technological knowledge. To this end, we studied how technological knowledge has accumulated across technology domains over a 25year period in the USPTO. Our analysis showed that the process of recombinant growth driving the accumulation of public technological knowledge is far from combinatorially unconstrained. Rather, at any point in time, the rate of future accumulation of public technological knowledge is affected in important and predictable ways by the extent to which the body of accumulated prior knowledge in a technology domain is specialized. Our results provide a relevant starting point to make current models of public knowledge growth more realistic and useful. 
Furthermore, our study explicates a framework and a methodology that can be used to investigate other explanatory mechanisms.

The third contribution of this research is to shed new light on the widely acknowledged fact that the domains of human knowledge grow at widely different rates (Nelson 2003). Earlier studies have argued that these differences depend on "demand-side" forces (e.g., Schmookler 1966), as well as on supply-side factors (e.g., Rosenberg 1974, 1983) such as the strength of the link between scientific knowledge and practical know-how, and relatedly, the difficulty of doing precise, reliable and generalizable experimentation (Nelson 2003). By explicating how the intertwined effects of knowledge specialization and knowledge brokerage affect the growth of technology domains, our study unveiled a previously unexplored mechanism that explains why certain domains of technological knowledge grow fast while others grow slowly or even stagnate. This theoretical advance may yield a practical contribution as well. In the knowledge-based economy, investing at the right time in the most profitable technology domain(s) is of high strategic importance because knowledge production capabilities develop in an irreversible fashion (Nelson and Winter 1982; Kogut and Zander 1992). While successful strategic positioning in an evolving technological landscape is a key competitive advantage both for organizations (Stuart and Podolny 1996) and for countries (Nelson 1993), managers and policy makers are typically faced with great uncertainty when making these strategic decisions. To aid them in sailing the high seas of the knowledge economy, we showed that a specialization-brokerage analysis improves our ability to predict both the risks and the rates of return associated with investments in a given portfolio of knowledge domains.

\section{Limitations and Opportunities for Future Research}

In order to focus on the dynamics of technological accumulation, we abstracted away from the actors that participate in and organize the inventive process. Thus, we were unable to analyze in any detail how individuals, teams, organizations, institutions and inter-organizational networks interact to produce aggregate outcomes. For example, we could observe the body of knowledge accessed by a given technological community, but we could not observe whether there is "resource partitioning" (Carroll 1985) within technological communities, at what level (e.g., individual, firm, etc.) that would take place, or what it might mean for the dynamics of knowledge recombination and growth. Similarly, while our study showed that the processes of specialization and brokerage are crucial to understand the growth of technology domains, we did not observe how these processes occur.

Our theory might be applied to lower levels of analysis. For example, it is well-known that business groups tend to experience diminishing returns over time (Granovetter 2005). Our conjecture is that this phenomenon may, in part, result from a decreasing ability to generate novel ideas and technologies. At the outset, organizations enter a business group with distinctive competencies and 
specializations, thereby pooling a diversified stock of knowledge and generating recombinant potential through knowledge brokerage. As time passes, however, knowledge exchange relations tend to strengthen within the group. This fosters efficient knowledge generation but also progressively depletes the recombinant potential available to the business group. Hence, new business groups should yield more innovative ideas and technologies, and thus greater returns on average, than long-established business groups. However, new business groups should also run greater risks of failure due to the cognitive and communication difficulties associated with recombining heterogeneous technologies, competences and knowledge trajectories. Useful insights could be gained if future studies explored the effects and dynamics of knowledge specialization and knowledge brokerage at the level of business groups, and more generally across units of analysis other than the technology domain.

The present study focused on the growth of publicly accessible, codified knowledge. In so doing, we glossed over the role of tacit knowledge. By definition, tacit knowledge tends to remain private and it can only partially be transmitted beyond an inventor's proximate social network. While tacit knowledge contributes to the accumulation of public knowledge to a limited degree, this doesn't mean that the generation and exchange of tacit knowledge is irrelevant for the progress of public knowledge. On the contrary, knowledge that is codified and publicly accessible is unlikely to be understood and effectively recombined unless it is complemented by related tacit and taken-for-granted notions (Gavetti and Levinthal 2000). Precisely because tacit and codified knowledge are complementary dimensions of the same phenomenon (Polanyi 1958, 1967; Cowan et al. 2000), it seems reasonable to assume that the unobserved flows of tacit knowledge occurring within and between technology domains are largely congruent with the observable flows of codified knowledge. Nonetheless, it would be ideal to study directly the role of tacit knowledge in the accumulation of public knowledge. While this goal may be hard to achieve with a large-scale quantitative research design, more appropriate methodological approaches and analytical techniques may be borrowed (or, one may say, recombined) from the large body of work on organizational routines (Nelson and Winter 1982).

\section{Notes}

1. The term "knowledge-based economy" is used for those economies where knowledge is more important for production than capital, labor and material resources, which holds for increasingly large parts of our modern economy.

2. A few authors distinguish between knowledge generated by inventions as a result of knowledge recombination, and knowledge generated by discovering empirical regularities. One may argue that even the latter mode of knowledge generation is ultimately combinatorial, because it involves synthesizing data and less general knowledge available at the time of discovery, some of which is embodied in scientific instruments. For that reason, DNA, for example, could not have been discovered in 
the Middle Ages.

3. Reported in Jones (2005:3).

4. Moreover, generating new knowledge can blur with other notions. For example, when a mathematics student learns the principles of calculus, his or her personal knowledge grows while no new knowledge is created in society at large. At the level of technology domains, it is much easier to keep new and existing knowledge apart.

5. Our conception of technology domains is therefore identical to the one adopted in the literature on epistemic communities. While technology domains are analytical categories that pertain to the partitioning of technological knowledge into technicallybased categories, these analytic categories do not merely reflect objective properties of the knowledge. Rather, the categories defining technology domains co-evolve with the "embedding circumstances" prevailing within distinct networks of practice (Brown and Duguid 2001) and thus with the cultural and institutional arrangements of distinct social (epistemic) communities (Knorr-Cetina 1999). However, our focus differs from studies of epistemic communities in two ways. First, rather than investigating epistemic communities against the background of technology domains, we focus directly on technology domains. Second, rather than emphasizing how the categorical boundaries defining technology domains are negotiated and change over the course of time, we emphasize that after they become culturally and institutionally embedded, definitions of technology domains are fairly stable.

6. This graphic difference between the literatures on diffusion and cognition (i.e., knowledge search) set aside, it is clear that knowledge recombination, be it brokerage or specialization, is a special case of knowledge diffusion, in this case of ideas from multiple sources to a target while being modified and recombined. The two literatures are consistent and complementary, one focusing on the generation of new knowledge and the other on the transmission of it.

7. Knowledge spillover is a broader concept than knowledge recombination. When used to describe the process of knowledge generation, an idea that spills over is one that becomes an input of recombination, contributing to the generation of a new idea. For an extensive discussion, see Jones (2005).

8. This conception of niche as a relationally defined position in a network is similar to, and inspired by, the one employed at the level of the individual invention by Podolny and Stuart (1995).

9. A mathematical representation of our hypotheses is reported in Appendix 1, which is available at http://www.unisi.ch/print/personalinfo? $\mathrm{id}=1529$.

10. These direct and indirect mechanisms do not have an equally strong impact on a domain's specialization, and this should be accounted for. Given the structure of our data, more than 90 percent of a domain's specialization is captured by the first two mechanisms.

11. The very few primary classes which have either emerged or disappeared from the USPTO classification during our observation period are not reported in the NBER patent and patent citations database. Hence, consistent with our theoretical approach and empirical focus, our analyses are based on technology domains whose boundaries were stable and institutionally recognized during the whole observation period.

12. Note that as a consequence of aggregating patent citations, a domain can have a loop, 
or a reflexive tie, whereas an individual patent can't cite itself.

13. We checked the data for cases when $s_{i j}=0$ while $s_{i j}>0$, since one could argue that despite requirement (3) above, $i$ would then still slightly specialize on $j$. That was hardly ever the case, leaving our results unaffected.

14. Thus $p_{i q}=\left(h_{q i}+h_{q i}\right) / \sum_{k}\left(h_{i k}+h_{k i}\right)$ and $p_{q j}=\left(h_{q j}+h_{j q}\right) / \Sigma_{z}\left(h_{q z}+h_{z q}\right)$, but index variable $z$ stands for nodes in $q$ 's ego network, including $q$, thereby allowing $q$ to have reflexive ties while $i \neq j$, like in Burt's model. To check for programming errors, each of the authors computed specialization with a different program and we correlated the results afterwards. Apart from rounding, the results were identical.

15. In the literature, the Herfindahl Index has been used to measure the degree of technological specialization of firms, industries and countries, indicating the extent to which their patent citations are concentrated among patent classes (e.g., von Tunzelmann 1998). Our network-based conceptualization of specialization may be regarded as an extension of the Herfindahl index that weighs the concentration of patent citations across patent classes by two additional terms. The first term weighs the extent to which the cited patent classes cite one another, indicating similarity or homogeneity among a focal domain's source domains. The second term weighs the extent to which a cited class cites back the focal technology domain, indicating similarity or homogeneity among the focal and source domains.

16. Network disturbance models exploit available information on the network structure of the data to account for the effects of possible network autocorrelation in the residuals. See Leenders (2002) for an extensive treatment of network autocorrelation models.

17. Because it entirely removes between-unit variation, the fixed-effects model provides a conservative approach yielding consistent estimates even in the presence of unobserved heterogeneity (Hsiao 2003). In contrast, based on a Hausman specification test (Hausman 1978), we cannot conclude that the estimates of the random-effects model are consistent in our case. Nonetheless, we chose to report the results of both the fixed-effects and the random-effects models because the latter makes it possible to estimate the effects of time-invariant control variables. Therefore, in reading the results of our analyses, one should rely primarily on the fixed-effects model, while the random-effects model is reported to show that the estimates pertaining to our variables of interest are not significantly altered by time-invariant controls.

18. As a further warranty that our analyses are not unduly biased by the presence of very small domains, we also ran all of the analyses reported in this article on samples based on technology domains that had, respectively, at least 50 and at least 100 patents granted within a given time interval. Although the sample size reduced to 1,530 and 1,440 observations, respectively, the estimations yielded qualitatively identical results to those reported. In fact, the only noticeable difference was that the estimates pertaining to our variables of interest had higher t-values and, hence, higher significance levels when we excluded the smallest domains. Furthermore, we have also collected data on the average $R \& D$ expenditure of technology domains. Because many R\&D data were missing, we chose to report the models with the R\&D control in Appendix 2, which is available at http://www.unisi.ch/print/personalinfo?id=1529. Our estimates of interest were unaffected by the R\&D control.

19. In a model not reported, we also included a covariate for the number of firms patenting in each technology domain in any time interval. Although this covariate explained a very large portion of the variance in our dependent variable, the results pertaining to our hypothesized effects remained virtually identical. We chose not to 
include this control variable because the number of firms patenting in a domain may depend on the growth of the domain, creating a potential endogeneity problem.

\section{References}

Abernathy, William, and James M. Utterback 1978. "Patterns of Innovation in Technology." Technology Review 80(7):40-47.

Albert, M., D. Avery, F. Narin and P. Mcallister. 1991. "Direct Validation of Citation Counts as Indicators of Industrially Important Patents." Research Policy 20(3):251-59. Alcácer, Juan, and Michelle Gittelman. 2006. "How Do You Know What You Know? The Role of Inventors and Examiners in the Generation of Patent Citations." Review of Economics and Statistics 88(4):774-79.

Almeida, Paul. 1996. "Knowledge Sourcing by Foreign Multinationals: Patent Citation Analysis in the US Semiconductor Industry." Strategic Management Journal 17(Winter Special Issue):155-65.

Anderson, John R., and Ross Thompson. 1989. "Use of Analogy in a Production System Architecture.” Pp. 267-97. Similarity and Analogical Reasoning. S. Vosniadou and A. Ortony, editors. Cambridge University Press.

Arrow, Kenneth J. 1962. "Economic Welfare and the Allocation of Resources for Inventions." Pp. 609-26. The Rate and Direction of Inventive Activity: Economic and Social Factors. R.R. Nelson, editor. Princeton University Press.

Becker, Howard Saul. 1982. Art Worlds. University of California Press.

Boland, Richard J., and Ramkrishnan V. Tenkasi. 1995. "Perspective Making and Perspective Taking in Communities of Knowing." Organization Science 6(4):350-72.

Brown, John Seely, and Duguid, Paul. 2001. "Knowledge and Organization: A SocialPractice Perspective." Organization Science 12(2):198-213.

Burt, Ronald S. 1992. Structural Holes: The Social Structure of Competition. Harvard University Press.

. 2004. "Structural Holes and Good Ideas." American Journal of Sociology 110(2):349-99.

Cantwell, John. 1989. Technological Innovation and Multinational Corporations. Basil Blackwell.

Carroll, Glenn R. 1985. "Concentration and Specialization: Dynamics of Niche Width in Populations of Organizations." American Journal of Sociology 90(6):1262-83.

Chase, W.G., and Herbert A. Simon. 1973. "The Mind's Eye in Chess." Visual Information Processing. W.G. Chase, editor. Academic Press.

Cohen, Jonathan D., and Gary Aston-Jones. 2005. "Decision amid Uncertainty." Nature 436(July 27):471-72.

Cohen, Wesley M., and Daniel A. Levinthal. 1990. "Absorptive-Capacity: A New Perspective on Learning and Innovation.” Administrative Science Quarterly 35(1):128-52.

Collins, Randall. 1998. The Sociology of Philosophies: A Global Theory of Intellectual Change. Belknap.

Cowan, Robin, Paul A. David and Dominique Foray. 2000. "The Explicit Economics of Knowledge Codification and Tacitness." Industrial and Corporate Change 9(2):211-53.

Davis, Gerald F., and Christopher Marquis. 2005. "Prospects for Organization Theory in the Early Twenty-First Century: Institutional Fields and Mechanisms." Organization Science 16(4):332-43.

Davis, Philip J., and Ruben Hersh. 1982. The Mathematical Experience. Birkhauser. 
De Solla Price, Derek J. 1965. "Networks of scientific papers." Science 149(July 30):510-15. Diamond, Jared. 1997. Guns, Germs, and Steel: The Fates of Human Societies. W.W. Norton. 2001. "Unwritten Knowledge." Nature 410(March 29):521.

Dosi, Giovanni. 1982. “Technological Paradigms and Technological Trajectories." Research Policy 11(3):147-62.

Dunbar, Kevin. 1996. "How Scientists Think: Online Creativity and Conceptual Change in Science." Conceptual Structures and Processes: Emergence, Discovery and Change. T.B. Ward, S.M. Smith and S. Vaid, editors. APA Press.

Earls, E., H. Smith, L. Wolf, R. Saifer, E. Rishell, D. Russell and C. Rademaker. 1997. Examiner Handbook to the U.S. Patent Classification System. Washington, DC: United States Patent and Trademark Office.

Eisenhardt, Kathleen M., and Behnam N. Tabrizi. 1995. "Accelerating Adaptive Processes: Product Innovation in the Global Computer Industry." Administrative Science Quarterly 40(1):84-110.

Fleming, Lee. 2001. "Recombinant Uncertainty in Technological Search." Management Science 47(1):117-32.

Fleming, Lee, Santiago Mingo and David Chen. 2007. "Collaborative Brokerage, Generative Creativity, and Creative Success." Administrative Science Quarterly 52(3):443-75 .

Foray, Dominique. 2006. Economics of Knowledge. The MIT Press.

Frost, Tony S. 2001. "The Geographic Sources of Foreign Subsidiaries' Innovations." Strategic Management Journal 22(2):101-23.

Gavetti, Giovanni, and Daniel Levinthal. 2000. "Looking Forward and Looking Backward: Cognitive and Experiential Search." Administrative Science Quarterly 45(1):113-37.

Gilfillan, S.C. 1935. The Sociology of Innovation. Follett Publishing.

Gittelman, Michelle, and Bruce Kogut. 2003. "Does Good Science Lead to Valuable Knowledge? Biotechnology Firms and the Evolutionary Logic of Citation Patterns." Management Science 49(4):366-82.

Granovetter, Mark. 2005. "Business Groups and Social Organization.” Pp. 429-50. The Handbook of Economic Sociology. N.J. Smelser and R. Swedberg, editors. Princeton University Press.

Griliches, Zvi. 1979. "Issues in Assessing the Contribution of Research and Development to Productivity Growth.” Bell Journal of Economics 10(1):92-116.

. 1990. "Patent Statistics as Economic Indicators: A Survey." Journal of Economic Literature 28(4):1661-1707.

Guimerà, Roger, Brian Uzzi, Jarrett Spiro and Luis A. Nunes Amaral. 2005. "Team Assembly Mechanisms Determine Collaboration Network Structure and Team Performance." Science 308(April 29):697-702.

Hall, Bronwyn, Adam B. Jaffe and Manuel Trajtenberg. 2001. "The NBER Patent Citations Data File: Lessons, Insights and Methodological Tools.” NBER Working Paper 8498. . 2005. "Market Value and Patent Citations." RAND Journal of Economics 36(1):16-38.

Hargadon, Andrew B. 2002. "Brokering Knowledge: Linking Learning and Innovation." Research in Organizational Behaviour 24:41-85.

Harhoff, Dietmar, Francis Narin, F.M. Scherer and Katrin Vopel 1999. "Citation Frequency and the Value of Patented Inventions." Review of Economics and Statistics 81(3):511-15. 
Hausman, Jerry A. 1978. “Specification Tests in Econometrics.” Econometrica 46(6):1251-71. Hayes, John R. 1989. The Complete Problem Solver. Erlbaum.

Henderson, Rebecca, Adam B. Jaffe and Manuel Trajtenberg. 2005. "Patent Citations and the Geography of Knowledge Spillovers: A Reassessment: Comment." American Economic Review 95(1):450-60.

Hicks, Diana, Tony Breitzman, Dominic Olivastro and Kimberly Hamilton. 2001. "The Changing Composition of Innovative Activity in the US: A Portrait Based on Patent Analysis." Research Policy 30(4):681-704.

Holyoak, Keith J., and Paul Thagard. 1995. Mental Leaps: Analogy in Creative Thought. MIT Press.

Hsiao, Cheng 2003. Analysis of Panel Data. Cambridge University Press.

Jaffe, Adam B., Michael S. Fogarty and Bruce A. Banks. 1998. "Evidence from Patents and Patent Citations on the Impact of NASA and other Federal Labs on Commercial Innovation.” Journal of Industrial Economics 46(2):183-205.

Jaffe, Adam B., and Manuel Trajtenberg. 1999. "International Knowledge Flows: Evidence from Patent Citations." Economics of Innovation and New Technology 8(1):105-36.

. 2002. Patents, Citations, and Innovations: A Window on the Knowledge Economy. MIT Press.

Jaffe, Adam B., Manuel Trajtenberg and Michael S. Fogarty. 2000. "Knowledge Spillovers and Patent Citations: Evidence from a Survey of Inventors." American Economic Review 90(2):215-18.

Jones, Charles I., 2005. "Growth and Ideas." Pp. 1063-1111. Handbook of Economic Growth. P. Aghion and S. Durlauf, editors. Elsevier.

Katila Riitta, and Gautam Ahuja. 2002. "Something Old, Something New: A Longitudinal Study of Search Behavior and New Product Introduction." Academy of Management Journal 45(6):1183-94.

Kogut, Bruce, and Udo Zander. 1992. "Knowledge of the Firm, Combinative Capabilities, and the Replication of Technology." Organization Science 3(3):383-97.

Knorr-Cetina, Karin. 1999. Epistemic Cultures: How the Sciences Make Knowledge. Harvard University Press.

Krackhardt, David. 1987. "QAP Partialling as a Test of Spuriousness." Social Networks 9:171-86.

. 1988. "Predicting with Networks: Nonparametric Multiple Regression Analysis of Dyadic Data." Social Networks 10(4):359-81.

Kuhn, Thomas. 1962. The Structure of Scientific Revolutions. University of Chicago Press. Latour, Bruno 1987. Science in Action: How to Follow Scientists and Engineers Through Society. Harvard University Press.

Leenders, Roger T.A.J. 2002. "Modeling Social Influence Through Network Autocorrelation: Constructing the Weight Matrix.” Social Networks 24(1): 21-47.

Levene, Howard. 1960. "Robust Tests for Equality of Variances." Pp. 278-92. Contributions to Probability and Statistics. I. Olkin, editor. Stanford University Press.

Levinthal, Daniel, and Claus Rerup. 2006. "Crossing an Apparent Chasm: Bridging Mindful and Less Mindful Perspectives on Organizational Learning." Organization Science 17(4):502-13. March, James. 1991. "Exploration and Exploitation in Organizational Learning." Organization Science 2(1):71-87. 
2005. "Parochialism in the Evolution of a Research Community: The Case of Organization Studies." Management and Organization Review 1(1):5-22.

Marshall, Alfred. 1936. Principles of Economic, $8^{\text {th }}$ Edition. Macmillan \& Co.

Mokyr, Joel. 2002. The Gifts of Athena: Historical Origins of the Knowledge Economy. Princeton University Press.

Nelson, Richard. Editor. 1993. National Innovation Systems: A Comparative Analysis. Oxford University Press.

. 2003. "On the Uneven Evolution of Human Know-How." Research Policy 32(6): 909-22.

Nelson, Richard, and Sidney Winter. 1982. An Evolutionary Theory of Economic Change. Belknap Press.

Nolan, Patrick, and Gerhard Lenski. 2006. Human Societies: An Introduction to Macrosociology. Tenth Edition. Paradigm Publishers.

Patel, Pari, and Keith Pavitt. 1987. "Is Western Europe Losing the Technological Race?" Research Policy 16(1):59-85.

Patel, Pari, and Modesto Vega. 1999. "Patterns of Internationalisation of Corporate Technology: Location vs. Home Country Advantages.” Research Policy 28(2-3):145-55.

Podolny, Joel M., and Toby E. Stuart 1995. "A Role Based Ecology of Technological Change." American Journal of Sociology 100(5):1224-60.

Podolny, Joel M., Toby E. Stuart and Michael T. Hannan. 1996. "Networks, Knowledge, and Niches: Competition in the Worldwide Semiconductor Industry, 1984-1991." American Journal of Sociology 102(3):659-89.

Polanyi, Michael. 1958. Personal Knowledge: Towards a Post-Critical Philosophy. Routledge and Kegan Paul.

1967. The Tacit Dimension. Routledge and Kegan Paul.

Postrel, Steven. 2002. "Islands of Shared Knowledge: Specialization and Mutual Understanding in Problem-Solving Teams.” Organization Science 13(3):303-20.

Powell, Walter W., and Kaisa Snellman. 2004. "The Knowledge Economy." Annual Review of Sociology 30:199-220.

Rogers, Everett M. 2003. The Diffusion of Innovations, $5^{\text {th }}$ Edition. Free Press.

Romer, Paul. 1993. "Idea Gaps and Object Gaps in Economic Development." Journal of Monetary Economics 32(3): 543-73.

Rosenberg, Nathan. 1974. "Science, Invention and Economic Growth.” Economic Journal 84(March):90-108.

. 1983. Inside Black Box: Technology and Economics. Cambridge University Press.

Rosenkopf, Lori, and Michael L. Tushman. 1998. "The Coevolution of Community Networks and Technology: Lessons from the Flight Simulation Industry." Industrial and Corporate Change 7(2):311-46.

Schmookler, Jacob. 1966. Invention and Economic Growth. Harvard University Press.

Schumpeter, Joseph. 1939. Business Cycles. McGraw-Hill.

Simon, Herbert A. 1977. "Scientific Discovery and the Psychology of Problem Solving.” Pp. 286-337. Models of Discovery. Herbert A. Simon, editor. Reidel.

Simonton, D. Keith. 1991. "Emergence and Realization of Genius: The Lives and Works of 120 Classical Composers." Journal of Personality and Social Psychology 61(5):829-40. 
2000. "Creativity-Cognitive, Personal, Developmental, and Social Aspects." American Psychologist 55(1):151-58.

Smith, Adam. 1776. An Inquiry into the Nature and Causes of the Wealth of Nations. Strahan \& Cadell.

Soete, Luc. 1987. "The Impact of Technological Innovation on International Trade Patterns: The Evidence Reconsidered.” Research Policy 16(1):101-30.

Staudenmaier, John M. 1985. Technology's Storytellers: Reweaving the Human Fabric. MIT Press.

Stuart, Toby E., and Joel M. Podolny 1996. "Local Search and the Evolution of Technological Capabilities." Strategic Management Journal 17(Summer):21-38.

Sutton, Robert I., and Andrew Hargadon. 1996. "Brainstorming Groups in Context: Effectiveness in a Product Design Firm." Administrative Science Quarterly 41(3):685-718.

Trajtenberg, Manuel. 1990. "A Penny for Your Quotes: Patent Citations and the Value of Innovations." The Rand Journal of Economics 21(1):172-87.

Tushman, Michael L., and Philip Anderson. 1986. "Technological Discontinuities and Organizational Environments.” Administrative Science Quarterly 31(3):439-65.

Tushman, Michael, and Lori Rosenkopf. 1992. "On the Organizational Determinants of Technological Change: Toward a Sociology of Technological Evolution.” Research in Organizational Behavior 14:311-47.

Usher, Abbott Payson. 1954. A History of Mechanical Inventions, $2^{\text {nd }}$ Edition. Harvard University Press.

Utterback, James M., and Fernando F. Suárez. 1993. "Innovation, Competition, and Industry Structure." Research Policy 22(1):1-21.

VanLehn, Kurt, and Randolph M. Jones. 1993. "Learning by Explaining Examples to Oneself: A Computational Model.” Pp. 25-82. Foundations of Knowledge Acquisition: Cognitive Models of Complex Learning. S. Chipman and A.L. Meyrowitz, editors. Kluwer.

Vincenti, Walter G. 1990. What Engineers Know and How They Know It: Analytical Studies from Aeronautical History. John Hopkins University Press.

von Hayek, Friedrich. 1945. "The Use of Knowledge in Society." American Economic Review 35(4):519-30.

Von Tunzelmann, G.N. 1998. "Localized Technological Search and Multi-Technology Companies." Economics of Innovation and New Technology 6(2): 231-55.

Wagner, David G., and Joseph Berger. 1985. “Do Sociological Theories Grow?” American Journal of Sociology 90(4):697-728.

1986. "Programs, Theory, and Metatheory." American Journal of Sociology 92(1):168-82.

Walberg, H.J. 1988. "Creativity and Talent as Learning." Pp. 340-61. The Nature of Creativity: Contemporary Psychological Perspectives. R.J. Sternberg, editor. Cambridge University Press.

Walker, Amasa. 1867. The Science of Wealth: A Manual of Political Economy. Embracing the Laws of Trade, Currency, and Finance. $3^{\text {rd }}$ Edition. Little Brown and Company.

Weisberg, Robert W. 1993. Creativity: Beyond the Myth of Genius. Freeman and Company.

Weitzman, Martin L. 1996. "Hybridizing Growth Theory." American Economic Review 86(2):207-12. 
1998. "Recombinant Growth." Quarterly Journal of Economics 113(2):331-60.

Young, Allyn. 1928. "Increasing Returns and Economic Progress." The Economic Journal 38(152):527-42. 